\title{
A Comparative Study of Long-Term-Care Insurance for the Elderly in Qingdao, Nantong and Shanghai
}

\author{
Bing-Rong LI \\ Business management research center of TUFE, Tianjin University of Finance and Economics, \\ Tianjin, China \\ Email: libingrong@tjufe.edu.cn
}

Keywords: Long-term-care insurance, Elderly people, Government policy.

\begin{abstract}
Providing for the aged is a worldwide topic. As China is the most populous country in the world, its large population base and rapid progress in aging has attracted both the party and the country's attention. The report of the 19th CPC National Congress put stress on the construction of the social security system. It says "We will act on the policy requirements to help those most in need, to build a tightly woven safety net, and to build the necessary institutions, as we works to develop a sustainable multi-tiered social security system that covers the entire population in both urban and rural areas, with clearly defined rights and responsibilities, and support that hits the right level”. Based on a field study of Qingdao, Nantong and Shanghai, this paper put forward proposals for Tianjin's long-term-care insurance for the elderly.

The long-term care insurance is an inevitable consequence of the aging, even super-aging society. It serves as an indispensable basic public service for this long-life society.
\end{abstract}

\section{An Analysis of the Long-term-care Insurance in Qingdao}

Since 1987, Qingdao, featuring a large, soaring, aging population, has become one of the aging countries earlier than many others. By the end of 2016, the number of citizens aged over 60 had reached 1.68 million, accounting for $21.3 \%$ of the total population, which was 4.6 percentage points higher than the national average. The elderly population over 80 reached 265,000, 16.5\% of the elderly. By now, the aging society has witnessed an increase in the population of disabled and semi-disabled elderly, which has aroused concerns over health care for the aged.

In July 2012, Qingdao officially launched a long-term medical care insurance, which covered urban residents and those who worked in Qingdao. In January 2015, Qingdao realized the integration of urban and rural medical insurance, making it possible for rural residents to enjoy the benefits as well. On January 1st, 2017, Qingdao government issued" dementia zone" policies which were designed particularly for the elderly with dementia, providing institution guarantee. It is another groundbreaking practice after Qingdao carried out a protection for the aged with physical disability.

\section{An Analysis of the Long-term-care Insurance in Nantong}

Nantong is another city which has embraced an aging population. With its 20.075 million over-sixty-year-old in 2016 which accounts for $27.49 \%$ of the old group and 340,000 over eighty over $16 \%$, ageing population deserve more attention. In addition, Nantong City is also characterized by its fast-growing aging population and the large number of empty nesters.

In October 2015, A legislation named "Establishing a Basic Care Insurance System (on Trial)" was introduced and carried out from January 1, 2016.Supported by communities and related institutions, this home-based system aims to combine medical treatment and healthcare and covers people under the basic medical insurance for employees and basic medical insurance for residents in the urban areas (Changchuan District, Gangzha District, and the Municipal Economic and Technological Development Zone). Since the law was acted upon for more than one year, the system has attracted 1.14 million members and the annual fund has reached 114 million yuan. Over 3,000 people have enjoyed benefits from it. 


\section{An Analysis of the Long-term-care Insurance in Shanghai}

By the end of 2016, the number of elderly people aged 60 and above in Shanghai was 4.5797 million, accounting for $31.6 \%$ of the total population. The elderly population aged 80 and above was 796,600 , accounting for $17.4 \%$ of the over 60 population and $5.5 \%$ of the whole population. Among them, there were 1,160,300 aged people having no children, 311,100 of whom were over 80, and 283,300 living alone, increasing 19,400 compared to 2015 and 3.08 million of them were orphans.

"Pilot Measures for Long-term Care Insurance in Shanghai" was issued in early 2017 and piloted in Xuhui, Putuo and Jinshan. In the pilot phase, two types of personnel were covered: one group referred to those who were at the age of 60 or above and got approval of the basic old-age pension for urban employees in accordance with the regulations, another group included long-term care insurance participants who reached Level 2 to Level 6 by needs assessment and disability .

\section{Comparative Analysis of Long-term Care Insurance for Elderly People in Cities Like Qingdao, Nantong and Shanghai}

After research and analysis, the three cities have an approximate starting development direction under the general trend of population aging. At the same time, they enjoy different characteristics due to geographical distinctions, social and historical differences as well as economic imbalance.

\section{Commonness of the Three Regions}

\section{A Large Population Base and an Increasing Population}

All these cities have become aging population areas at a respectively early time. Among them, Shanghai is the first one in China to embrace aging population and Nantong and Qingdao entered the aging society 17 years and 12 years earlier than the average. The three cities are challenged by the large, fast-growing aging population and a large proportion of senior citizens. At the same time, an increase in empty nesters caused by the regional economic growth has been a more and more prominent social problem in recent years.

\section{Government Policy and Financial Support}

Attaching great importance to the role of insurance in the elderly care service, the local governments of the three places strongly support the development of long-term care insurance and has made clearly of community, home, and institutional pensions by issuing relevant policies to push forward the system in terms of development principles, planning, and facility construction. Furthermore, financial support policies have been carried out, as another support for long-term care system.

\section{Active Cooperation and Rural and Urban Overall Plan}

Adhere to the principle of full coverage and basic guarantee, the integrated development is promoted at the same speed to avoid some broken situations such as double standards and urban first, speeding up the integration and equalization of urban and rural areas. As the long-term care development is based on urban and rural integration, it constitutes a systematic project which involves multiple departments 'work.

All three cities have established specific organizations, improved their functions at all levels, clarified the responsibilities of the relevant departments, and effectively strengthened the coordination of policies, forming a complete system for the integration of urban and rural development.

\section{Introduction of the Third-party Assessment Agencies}

They all have introduced third-party assessment agencies to identify insured personnel. Qingdao entrusts China Life Insurance Company, Shanghai entrusts the Municipal Medical Insurance Center, and Nantong entrusts the Municipal Labor Accreditation Center. Besides, they employ medical 
experts to jointly form an assessment team to assess the site. After the insured person submits an application, and if there is no objection to the results of the disability assessment through the five-step stipulation procedures such as the initial review, on-site assessment, neighborhood community survey, and public announcement, the assessment will be issued by a third-party assessment agency. The three cities constantly devote great energy to asking fixed-point agencies to establish and improve evaluation systems for nursing services, establish personalized nursing service plans, timely evaluate nursing effects, and constantly adjust and optimize service content.

\section{Analysis of the characteristics of the three cities}

\section{Pioneering Short-Term Care Service for the Elderly with Dementia in Qingdao}

From January 1, 2017, Qingdao's management measures on "Alzheimer zone" were formally implemented, making all demented old people the first group in the country to get institutional protection. The short-term care (breathing service) is designed to provide day-to-day care for the dementia elderly and it will last form a total of days to dozens of days, no more than 60 days in a year. It was very helpful in providing those family members some breathing space, who had taken care of the dementia elderly for a long time and have great pressure.

\section{The first Care Assistant System in Shanghai}

As a newly created profession, care assistant is different from the professional nurses in medical institutions. It is developed specifically for medical care, having a series of titles with local characteristics in Shanghai. The personnel who pass the primary and intermediate examinations for nursing care workers in nursing homes have the same or higher income levels as professional nurses in Shanghai.

\section{Multiple Channels of Fund Raising in Nantong}

In Nantong, in addition to personal payment, fund raising of medical insurance, and accident financial assistance from government accident, donations from social organizations such as enterprises, organizations, charities and individuals also at play. The Nantong Municipal Finance Bureau allocates a certain amount of funds from the Welfare Lottery Public Welfare Fund annually to enrich basic care.

\section{Nantong City Introduces Third Party Organizations to Manage Insurance Funds}

The local government has introduced four insurance companies, namely Ping an Insurance, Taiping Insurance, China Life, and Pacific Insurance, through the government tendering process. During the tendering process, the insurance company asked for a 1\%-3\% service fee and would supervise the operation of long-term care insurance in accordance with $45 \%, 30 \%, 15 \%$, and $10 \%$ - the distribution ratio of insurance funds. Third-party assessment agencies set up a special service window near the Social Security Bureau, the Care Service Center, and special personnel at the front desk providing necessary services such as acceptance, authentication, assessment, and supervision.

\section{Strengthening Assessment of the Service Agencies in Nantong}

In order to strengthen and standardize management, improve the service quality of fixed-site care institutions, and promote the development of the care service market, Nantong has formulated the Interim Measures for the Assessment of the Point-of-care Services Provided by the Nantong Care Insurance Service, which has required that different types assessed according to nursing bed care services and home care services as different institutions offer various kinds of service.

\section{Laying Different Emphasis in Three Cities}

Qingdao's long-term care insurance mainly focuses on medical care, focusing on the protection of disabled and semi-disabled old people. It is an enrichment, expansion, and improvement of the basic medical insurance system.

Shanghai Long-term Care Insurance is divided into basic life care and common clinical care. It provides in-home care or community day care and related medical care services for home-based 
insured persons; provides basic life care for hospitalized insured persons and related medical care services; provides inpatient medical care services for those insured hospitalized in designated medical institutions.

Nantong City's long-term care insurance is based on home-based, community-based, and institutional-supported "combination of medical care and health care," Care insurance and medical insurance are relatively independent and connected with each other, and they are under different management.

\section{What can be learned by Tianjin?}

Based on the above data analysis and field surveys on the implementation of long-term care insurance for the elderly in the three places, inspirations of the future establishment of long-term care insurance in Tianjin are as follows:

\section{Diversifying Funding Channels of Long-Term Care Insurance}

The long-term care insurance for the elderly should be served as a social insurance welfare so the source of funding should include government finances, employers and individuals. Adopting a compulsory method, it should levy tax on people over 45 years old by different proportions. But those who enjoy low-income benefits should be fully funded by the government. At the same time, funding from social organizations and individuals such as enterprises, organizations, and charities are also acceptable so as to alleviate financial pressure on all parties.

It is particularly recommended that while speeding up the implementation of long-term care social insurance, matching commercial insurance products should be launched as a complement.

\section{Establishing Long-term Care Insurance for Specific Groups}

\section{Long-term Care Insurance Coverage}

Long-term care insurance is a type of insurance established specifically for the elderly population. On the ground of this particular group, there is also a specific population who cover the insurance premiums. It is recommended that the population between the ages of 45 and 50 be forced to pay long-term care insurance. This not only eases the economic pressure of young people, but also highlights that the long-term care insurance is elderly-based.

\section{Enjoy Long-term Care Insurance}

In the trial phase, it is recommended within a certain period of time that executors choose "completely disabled seniors" as their clients as it would be much easier to make assessments and judgments for the. Since the disabled have limited and relatively stable demands for life, and their conditions are much regularly available, there will be less challenge in implementing the project. After gaining more experience, institution leaders can expand their insured groups and promote the project on a large scale.

\section{Formulating Unified and Complete Service Standards}

In an attempt to ensure the sustainable and rational development of long-term care insurance, it is necessary to formulate a series of uniform, operable, and continuous standards.

\section{Unified standards for Care Service Level system}

The government need to combine the disability level, nursing grading and insurance mechanism according to " Activities of Daily Living Assessment Scale”, making the nursing standards match for different levels of disability. According to the service time and costs, service standards would be formulated to serve home-based care, institutional pensions, and community care.

\section{Unified Mechanism and System of Elderly Disability Assessment}

It would be helpful to establish a unified evaluation system for the elderly disabled, including independent professional assessment agencies and assessment standards. With reference to 
international experience, the evaluation agency shall be undertaken by a social organization or a third-party assessment agency. The relevant government agencies shall sign a contract to ensure that the assessment of disability will be carried out fairly and objectively.

\section{Unified standards for Government Subsidies}

Depending on the severity, the government can provide appropriate subsidies for care service agencies and care workers. By classifying their clients' health conditions into mild, moderate, and severe level, the government should pay in kind and lay stress on home care.

\section{Unified Standards for the Long-term Care Workers}

The local government needs to establish the basic qualification standards for care workers, carry out standardized management as well as regular assessments.

\section{Creating a Standardized Management}

\section{Implementing Overall Management}

At this point, there exist a considerable number of service institutions, especially private service institutions, failing to give full play to their effectiveness with excessive vacancy of beds for various reasons. It is suggested that the relevant regulatory agencies should cooperate with them, achieving integrated management. In this way, once the elderly who have purchased insurance are completely disabled, the family members can contact the management agency. Through comprehensive evaluation, the management agency will make overall coordination and recommend them to the suitable institution with certain qualifications to be offered long-term care services.

\section{Enhancing Supervision}

The management agencies must earnestly perform their duties and use standardized methods to intensify the day-to-day supervision, building a formal supervisory process. They should be good at finding problems and solving them in a timely manner, which enables the elderly-care agencies to provide qualified service and avoid financial losses caused by vacancy in the beds.

\section{Establishing a long-time volunteering-time accumulation system}

On one hand, it is required to strengthen the training of long-term care volunteers so as to form a mechanism which enables professionals to lead volunteers. In addition, experts and scholars specialized in social work and nursing are to be invited to provide training for long-term care volunteers, improving their professional service capabilities.

On the other hand, a long-term volunteering-time accumulation system need to be established, therefore volunteers can enjoy some benefits according to their service time. Through setting up a special agency to make a record, volunteers can receive a certificate which is issued by relevant agencies and records the time and grade of service after the service expires. When necessary, by virtue of this certificate, they can enjoy free care services for the same period, creating a virtuous circle.

\section{References}

[1] Yansui Yang: “China May Enter the "Super Ageing Society” in Advance”, Xinhua Daily, July 18, 2014, 9th edition.

[2] National Bureau of Statistics of the People's Republic of China, China Statistical Yearbook (2016)

[3] Ministry of Civil Affairs of the People's Republic of China and Statistical Yearbook of China's Civil Affairs (2016) [Z], Beijing: China Statistics Press, 2016

[4] Report at the 19th National Congress of the Communist Party of China [Z], Beijing: People's Publishing House, October 18, 2017 
[5] http://www.china.com.cn/zhibo/2017-11/01/content_41820919.htm

[6] Yan Tang. Nantong, An analysis on the Development of the Service Industry [J]. Anhui Literature (the second half of the month). 2016(05) 